\title{
Homogeneous and Heterogeneous Photocatalysis
}

edited by

\section{Ezio Pelizzetti}

Department of Analytical Chemistry, University of Turin,

Turin, Italy

and

\section{Nick Serpone}

Department of Chemistry, Concordia University,

Montreal, Canada

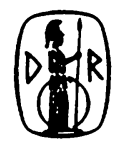

D. Reidel Publishing Company

Dordrecht / Boston / Lancaster / Tokyo

Published in cooperation with NATO Scientific Affairs Division 
Proceedings of the NATO Advanced Research Workshop on

Homogeneous and Heterogeneous Photocatalysis

Maratea, Potenza, Italy

September 1-7, 1985

\section{Library of Congress Cataloging in Publication Data}

NATO Advanced Research Workshop on Homogeneous and Heterogeneous Photocatalysis (1985: Maratea, Italy)

Homogeneous and heterogeneous photocatalysis.

(NATO ASI series C, Mathematical and physical sciences; vol. 174)

"Proceedings of the NATO Advanced Research Workshop on Homogeneous and Heterogeneous Photocatalysis, Maratea, Potenza, Italy, September 1-7, 1985." Includes indexes.

1. Photochemistry-Congresses. 2. Catalysis-Congresses. I. Pelizzetti, Ezio, 1944- , II. Serpone, Nick, 1939- . III. Series.

QD701.N34 $1985 \quad 541.3^{\prime} 5 \quad 86-3152$

ISBN-13: 978-90-277-2221-8

e-ISBN-13: 978-94-009-4642-2

DOI: $10.1007 / 978-94-009-4642-2$

Published by D. Reidel Publishing Company

P.O. Box 17, 3300 AA Dordrecht, Holland

Sold and distributed in the U.S.A. and Canada

by Kluwer Academic Publishers,

190 Old Derby Street, Hingham, MA 02043, U.S.A.

In all other countries, sold and distributed

by Kluwer Academic Publishers Group,

P.O.Box 322, 3300 AH Dordrecht, Holland

D. Reidel Publishing Company is a member of the Kluwer Academic Publishers Group

All Rights Reserved

๑ 1986 by D. Reidel Publishing Company, Dordrecht, Holland.

\section{Reprint of the original edition 1986}

No part of the material protected by this copyright notice may be reproduced or utilized in any form or by any means, electronic or mechanical, including photocopying, recording or by any information storage and retrieval system, without written permission from the copyright owner. 


\section{NATO ASI Series}

\section{Advanced Science Institutes Series}

A series presenting the results of activities sponsored by the NATO Science Committee, which aims at the dissemination of advanced scientific and technological knowledge, with a view to strengthening links between scientific communities.

The series is published by an international board of publishers in conjunction with the NATO Scientific Affairs Division
A Life Sciences
Plenum Publishing Corporation
B Physics
London and New York
C Mathematical
D. Reidel Publishing Company
and Physical Sciences
Dordrecht, Boston, Lancaster and Tokyo
D Behavioural and Social Sciences
Martinus Nijhoff Publishers
E Engineering and
The Hague, Boston and Lancaster
Materials Sciences
F Computer and Systems Sciences
G Ecological Sciences
Springer-Verlag
Berlin, Heidelberg, New York and Tokyo

Series C: Mathematical and Physical Sciences Vol. 174 
Homogeneous and Heterogeneous Photocatalysis 
TABLE OF CONTENTS

Foreword

$x i$

Organizing Committee

xiil

List of Lecturers

xiv

List of Chairmen and Participants

$x v i$

V. Balzani, A. Juris and F. Scandola

Photoinduced charge separation:

Requirements needed for ideal relays

and photosensitizers

F. Scandola, C.A. Bignozzi and V. Balzani

Photoinduced charge separation:

Towards the design of supermolecular

systems based on transition metal complexes

N. Serpone and E. Pelizzetti

Fundamental studies into primary events

in photocatalysis employing $\mathrm{CdS}$ and $\mathrm{TiO}_{2}$

semiconductors: Photoluminescence, laser

flash photolysis and pulse radiolysis

M. Grätzel

Dynamics of interfacial electron transfer reactions in colloldal semiconductor systems and water cleavage by visible light

L. Brus

Electronic Spectroscopy of semiconductor clusters

A. Harriman, P. Neta and M.C. Richoux

Catalysed decay of oxidising radicals

in water 
L.Y.C. Lee, K.S. Schanze, C. Giannotti and D.G. Whitten Photocatalysis and light-induced electron transfer reactions of tertiary amines

F. Baykut, G. Benlioğlu and G. Baykut Photocatalytic production of ascorbic acid. A secondary photosynthesis in plants

J.R. Bolton, J.A. Schmidt, A. Siemiarczuk,

M.D. Arsher and J.H. Wilford

Spectroscopic and electrochemical studies of photochemical electron transfer in linked donor-acceptor molecules

C. Franco and G. McLendon

Bifunctional porphyrins: Redox photochemistry of [meso(tritolyl (pyridyl Ru(III) ( $\left.\mathrm{NH}_{3}{ }^{\prime} \mathrm{L}^{\prime} \mathrm{I}^{\prime}\right)$ ) porphyrin] ( $\mathrm{L}^{\prime}=\mathrm{NH}_{3}$, pyridine, 5-Cl-pyridine)

V.H. Houlding and A.J. Frank

Linear chain platinum complexes as photocatalysts

O.I. Mícíc, M.T. Nenadovíc, T. Rajh, N.M. Dimitrijevíc and A.J. Nozik

Electron transfer reactions on extremely

small semiconductor colloids studied by

pulse radiolysis

O.Micic and D. Meisel

Nafion stabilized aqueous solutions of colloidal semiconductors

Y.-M. Tricot and J.H. Fendler

In situ generated catalyst-coated colloidal

semiconductor CdS particles in surfactant vesicles and polymerized surfactant vesicles

E. Amouyal

Development of catalysts for water photoreduction: Improvement, poisoning and catalytic mechanism 
Y. Haruvy, R. Rafaeloff and L.A. Rajbenbach

Radiolytic methods of preparation of colloidal and heterogeneous redox catalysts and their application in light-induced $\mathrm{H}_{2}$ generation from water

J. Kiwi

The effect of promoters on the photochemical water cleavage in suspensions of $\mathrm{Pt}$-loaded $\mathrm{TiC}_{2}$ with increased light to chemical conversion efficiency

A. Heller

Metallic catalysts on semiconductors:

Transparency and electrical contact properties;

D. Meissner, Ch. Sinn, R. Memming, P.H.L. Notten and J.J. Kelly

On the nature of the inhibition of electron transfer at illuminated p-type semiconductor electrodes

J. Manassen, D. Cahen, G. Hodes, R. Tenne and S. Licht The importance of solution kinetics in photoelectrochemical phenomena

N.S. Lewis, M.L. Rosenbluth, L.G. Casagrande and B.J. Tufts

Mechanistic aspects of semiconductor photoelectrochemistry: The behavior of $S i$ and GAAs in nonaqueous solvents

M.A. Fox

Charge injection into semiconductor particles Importance in photocatalysis

H. Kiseh

Hydrogen evolution and selective organic photosynthesis catalyzed by zinc sulfide

T. Sakata

Photocatalytic organic synthesis by use of semiconductors or dyes 
E. Papaconstantinou, P. Argitis, D. Dimoticali,

A. Hiskia and A. Ioannidis

Photocatalytic oxidation of organic compounds with heteropoly electrolytes. Aspects on photochemical utilization of solar energy

I. Ait Ichou, D. Bianchi, M. Formenti and S.J. Teichner Photoformation of hydrogen in liquid water in the presence of $\mathrm{Pt} / \mathrm{TiO}_{2}$ catalyst and organic impurities

G.A. Somorjai and M. Salmerun

Surface properties of catalysts. Iron and its oxides: Surface chemistry, photochemistry and catalysis

H. Van Damme, F. Bergaya and D. Challal

Photocatalysis over clay supports

G.N. Schrauzer, T.D. Guth, J. Salehi, N. Strampach, Liu Nan Hui and M.R. Palmer

Photoreduction and-oxidation of molecular nitrogen on titanium dioxide and titanium containing minerals

M. Halmann and $K$. Zuckerman

Photoassisted reduction of carbon and nttrogen compounds with semiconductors

P. Pichat

Adsorption and desorption processes in photocatalysis

R.I. B1ckley, R.K.M. Jayanty, V. Vishwanathan and J.A. Navio

Photo-induced processes at titanium dioxide surfaces

V. Augugllaro, L. Palmisano, M. Schiavello and

A. Sclafan 1

Photolysis of adsorbed phases: Ethanolc acid-insulators and semiconductors systems. Influence of acid-base properties 
M. Matsumura, Y. Saho and H. Tsubomura

Cadmium sulfide photocatalyzed hydrogen

production from aqueous solutions of sulfite

D. Cesareo, A. di Domenico, S. Marchini,

L. Passerini and M.L. Tosato

Environmental photochemistry of chlorinated

aromatics in aqueous media. A review of data

B.G. Oliver and J.H. Carey

Photodegradation of wastes and pollutants

in aquatic environment

D.F. Ollis

Heterogeneous photocatalysis for water

purification: Prospects and problems

K. Krist and R.V. Serauskas

A Gas Research Institute perspective on inorganic synthesis of gaseous fuels

E. Borgarello, N. Serpone, M. Barben1, C. Minero,

E. Pelizzetti and E. Pramauro

Putting photocatalysis to work

D. Meisel and D.F. Ollis

Panel discussion on the

Selective activation and conversion of molecules

J. Fendler and J. Bolton

Panel discussion on

Sensitization and immobilization of catalysts on various supports

G. McLendon and R. Memming

Panel discussion on

Electrocatalysis and photocatalysis 
Final Remarks

Author Index

Sabject Index 
FOREWORD

Ever since the oil crisis of 1973, researchers in various fields of chemistry have proposed various schemes to conserve energy, as well to convert the sun's abundant and limitless supply of energy to produce chemical fuels (e.g., hydrogen from water, ...). The enthusiasm had no previous parallel in the mid-1970's. Unfortunately, despite the several good proposals, the results have proven - in retrospect - somewhat disappointing from an economic viable point of view. The reasons for the meagre results are manyfold not the least of which are the experimental difficulties encountered in storage systems. Moreover, the lack of a concerted, well orchestrated interdisciplinary approach has been significant. By contrast, the chemical advances made in the understanding of the processes involved in such schemes have been phenomenal. A recent book on this issue (M. Gratzel, Energy Resources through Photochemistry and Catalysis, 1983) is witness to the various efforts and approaches taken by researchers. In the recent years, many more groups have joined in these efforts, and the number of papers in the literature is staggering !

One of the motives for organizing this NATO Advanced Research Workshop stemmed from our view that it was time to take stock of the accomplishments and rather than propose new schemes, it was time to consider seriously avenues that are most promising. For this very purpose, our approach, as we viewed 1t, was to bring together experts from the various chemical fields (Photochemistry, Electrochemistry, Catalysis, Colloid, Semiconductor, and Biochemistry) - an interdisciplinary approach - and from various NATO ( and non-NATO) countries to one meeting place such that we could fully and informally discuss recent achlevements and problems.

Our hope from this Workshop was that the participants would put forward and point out the important problens yet to resolve towards achieving a viable system for energy conversion and energy storage. Additionally, and by no means least, we saw the Workshop participants tackling other important issues regarding photocatalysis in the synthesis of chenically useful products, and in the environmental pollution area. 
The Workshop would not have been the same without the dedicateo help of the staff of the Hotel Villa del Mare, to whom we owe the creation of a very warm and pleasant atmosphere, conducive to scientific and social interactions among the participants.

Finally, we thank the Directors of the Scientific Affairs Division of NATO and of the Programme on Selective Activation of Molecules for granting us the financial support for a very fruitful Advanced Research Workshop.

Ezio Pelizzetti

Università di Torino

Torino - ITALY
Nick Serpone

Concordia Untversity

Montreal - CANADA

September 10, 1985 


\section{ORGANIZING COMMITTEE}

Prof. E. Pelizzetti

Dipartimento di Chimica Analitica

Università di Torino

via Pietro Giuria 5 - 10126 TORINO - ITALY

Prof. N. Serpone

Dept. of Chemistry

Concordia University

1455 de Maisonneuve - Blvd. West - MONTREAL - QUEBEC H3G 1M8 - CANADA

Dr. F. Cecchint

C.N.R.

via Nizza 128 - 00198 ROMA - ITALY

Dr. A. Harriman

The Royal Institution

21, Albemarle Street - LONDON WIX 4BS - U.K.

Prof. G. McLendon

Dept. of Chemlstry

University of Rochester

River Station - ROCHESTER - N.Y. 14627 - USA

Prof. F. Scandola

Dipartimento di Chimica

Università di Ferrara

v1a Borsar1 46 - 44100 FERRARA - ITALY 


\section{LIST OF LECTURERS}

Prof. M.A. Fox

Dept. of Chemistry

University of Texas

AUSTIN TX 78712-1167 - USA

Prof. M. Gratzel

Institut de Chimie Physique

E.P.F.L.

Ecublens - 1015 LAUSANNE - $\mathrm{CH}$

Dr. A. Heller

AT\&T Be11 Laboratories

600 Mountain Avenue

Murray H111 - NEW JERSEY 07974 - USA

Dr. B.G. Oliver

Environmental Contaminants Division

National Water Research Institute - Canada Centre for Inland Waters P.O.Box 5050 - BURLINGTON - ONTARIO L7R 4A6 - CANADA

Dr. P. Pichat

C.N.R.S. - Ecole Centrale de Lyon

Bat. Chimie

B.P. 163 - 69131 ECULLY CEDEX - FRANCE

Prof. G.N. Schrauzer

Dept. of Chemistry

University of California - San Diego

Revelle College - LA JOLLA - CALIF. 92093 - USA 
Prof. G.A. Somorjal

Dept. of Chemistry

University of California - Berkeley

BERKELEY - CALIFORNIA 94720 - USA

Dr. H. Van Damme

C.N.R.S. - Centre de Recerche sur le Solides a Organisation Cristialline Imparfaite

45045 ORLEANS CEDEX - FRANCE 


\section{LIST OF CHAIRMEN AND PARTICIPANTS}

\section{CANADA}

Dr. D. Belanger

Institut Nat. de la Recherche Scientifique

Case Postale 1020

Varennes - Quebec JOL 2 PO

Dr. E. Borgarello Dept. of Chemistry - Concordia University 1455 de Maisonneuve Blvd. West Montreal - Quebec H3G 1 M8

Prof. J. Bolton The University of Western Ontario Dept. of Chemistry

London N 6A 5B7

Dr.J.P. Dodelet Institut Nat. de la Recherche Scientifique Case Postale 1020

Varennes - Quebec JOL 2 PO

FRANCE

Dr. E. Amouyal Laboratoire de Physico-Chimie des Rayonnements Université Paris-Sud 91405 ORSAY CEDEX 
Dr. C. Giannotti C.N.R.S.

Institut de Chimie des Substances Naturelles 91190 GIF-SUR-YVELFE

Prof. S.J.Teichner Laboratoire de Thermodynamique et Cinetique Chimiques - Université Claude Bernard 43, Boulevard du 11 Novembre 1918 69622 VILLEURBANNE CEDEX

F.R. GERMANY

Prof. H. Kisch Institut fur Anorganische Chemie der Universitat Erlangen-Nurnberg

Egerlandstr. 1

D-8520 ERLANGEN

Prof. R. Memming Institut f. Physikalische Chemie Universitat Hamburg

Laufgraben 24

D-2000 HAMBURG 13

Dr. R. Millini Institut fur Anorganische Chemie der Universitat Erlangen-Nurnberg

Egerlandstr. 1

D-8520 ERLANGEN

GREECE

Dr. E. Papaconstantinou Chemistry Dept. N.R.C. Demokritos ATHENS 
ISRAEL

Dr. M. Halmann

Isotope Dept.

Weizmann Institute of Science

REHOVOT 76100

Dr. J. Manassen The Weizmann Institute of Science REHOVOT 76100

Dr. L.A.Rajbenbach Soreq Nuclear Research Center

YAVNE 70600

ITALY

Prof. G.G.Aloisi Dip. di Chimica - Università di Perugia via Elce di Sotto 8

06100 PERUGIA

Dr. R.Amade111 Centro di Fotochimica CNR via Borsari 46

44100 FERRARA

Prof. V.Augugliaro Istituto di Ingegneria Chimica Università di Palermo - Viale delle Scienze 90128 PALERMO

Prof. V.Balzani Istituto Chimico G.Ciamician Università di Bologna - via Selmi 2 40126 BOLOGNA 
Dr. M. Barbeni

Dip. di Chimica Analitica - Università di Torino via Pietro Giuria 5

10125 TORINO

Prof. C.A.Bignozzi Dip. di Chimica - Università di Ferrara via Borsari 46

44100 FERRARA

Dr. C.Chiorboli Centro di Fotochimica CNR via Borsari 46

44100 FERRARA

Dr. M. Ciano

FRAE CNR

via de Castagnoli 1

40126 BOLOGNA

Dr. A.di Domenico Istituto Superiore di Sanità

Dept. of Comparative Toxicology and Ecotoxicology viale Regina Elena 299

00161 ROMA

Prof. M.T.Indelli Dip. di Chimica - Università di Ferrara via Borsari 46

44100 FERRARA

Dr. A.Maldotti Dip. di Chimica - Università di Ferrara via Borsari 46

44100 FERRARA

Dr. C.Minero

Dip. di Chimica Analitica - Università di Torino via Pietro Giuria 5

10125 TORINO 
Dr. L.Palmisano Istituto di Ingegneria Chimica

Università di Palermo - Viale delle Scienze

90128 PALERMO

Dr. E.Passalacqua Istituto CNR di Metodi e Processi Chimici per la trasformazione e l'accumulo dell'Energia via S.Lucia Sopra Contesse 39

98013 PISTUNINA (MESSINA)

Prof. E.Pramauro Dip. di Chimica Analitica - Università di Torino via Pietro Giurta 5

10125 TORINO

Prof. M.A.Rampi Dip. di Chimica - Università di Ferrara via Borsari 46

44100 FERRARA

Prof. A.Sclafani Istituto di Ingegneria Chimica Università di Palermo - Viale delle Scienze 90128 PALERMO

Prof. L.Stradella Istituto di Chimica Generale e Inorganica Facoltà di Farmacia - Università di Torino via Pietro Giuria 9 10125 TORINO

Dr. M.L.Tosato

Istituto Superiore di Sanità Dept. of Comparative Toxicology and Ecotoxicology viale Regina Elena 299

00161 ROMA 
JAPAN

Dr. T. Sakata

Prof. H. Tsubomura

PORTUGAL

Dr. S. Costa

SPAIN

Prof. G.Munuera

Dr. J.A. Navio Santos
Institute for Molecular Science

MYODAIJI OKAZAKI 444

Laboratory for Chemical Conversion of Solar Energy and Dept. of Chemistry - Faculty of Engineering, Science - Osaka University

Toyonaka, OSAKA 560

Centro de Quimica Estrutural, Complexo I

Instituto Superior Técnico - Avenida Rovisco Pals 1096 LISBOA Codex
Departamento de Quimica General

Facultad de Quimica - Universidad de Sevilla SEVILLA

Departamento de Quimica General

Facultad de Quimica - Universidad de Sevilla SEVILLA 
SWITZERLAND

Dr. J.Kiwi

Institut de Chimie Physique

E.P.F.L. - Ecublens

1015 LAUSANNE

TURKEY

Prof. F. Baykut

Dept. of Chemical Engineering

Faculty of Engineering - University of Istanbul

Laleli - ISTANBUL

Dr. G. Baykut

Dept. of Chemical Engineering

Faculty of Engineering - University of Istanbul

Laleli - ISTANBUL

U.K.

Prof. M.Archer

Dept. of Physical Chemistry

University of Cambridge

Sensfield Road

CAMBRIDGE CB2 1EP

Prof. R.Bickley Scool of Studies in Chemistry

University of Bradford

BRADFORD BD7 1DP 
USA

Dr. L. Brus

AT\&T Be11 Laboratories

600 Mountain Avenue

Murray H1l1 - New Jersey 07974

Prof. J.H.Fendler Dept. of Chemistry

and Institute of Colloid and Surface Science

Clarkson University

POTSDAM - New York 13676

Dr. A.J.Frank

Solar Energy Research Institute

1617 Cole Boulevard

GOLDEN CO 80401

Dr. M.E.Gress

Dept. of Energy

Division of Chemical Sciences

WASHINGTON DC 20545

Dr. K.Krist

Gas Research Institute

8600 W. Bryn Mawr Ave.

CHICAGO IL 60631

Prof. N.S.Lewis Dept. of Chemistry

Stanford University

STANFORD CA 94305

Dr. D.Me1se1

Argonne National Laboratory

Chemistry Division

ARGONNE IL 60439

Dr. A.J.Nozik

Solar Energy Research Institute

1617 Cole Boulevard

GOLDEN CO 80401 
Prof. D.F.011is Chemical Engineering Dept.

North Caroline State University

RAYLEGH NC 27695-7905

Dr. S.Tunesi

University of Wisconsin

Dept. of Agricoltural Sciences

MADISON - Wisconsin 53706

Prof. D.G. Whitten Dept. of Chemistry

University of Rochester

ROCHESTER - New York 14627

YUGOSLAVIA

Dr. O.I.Micic

Boris Kidric Institute of Nuclear Sciences Vinca 11001 - BEOGRAD 


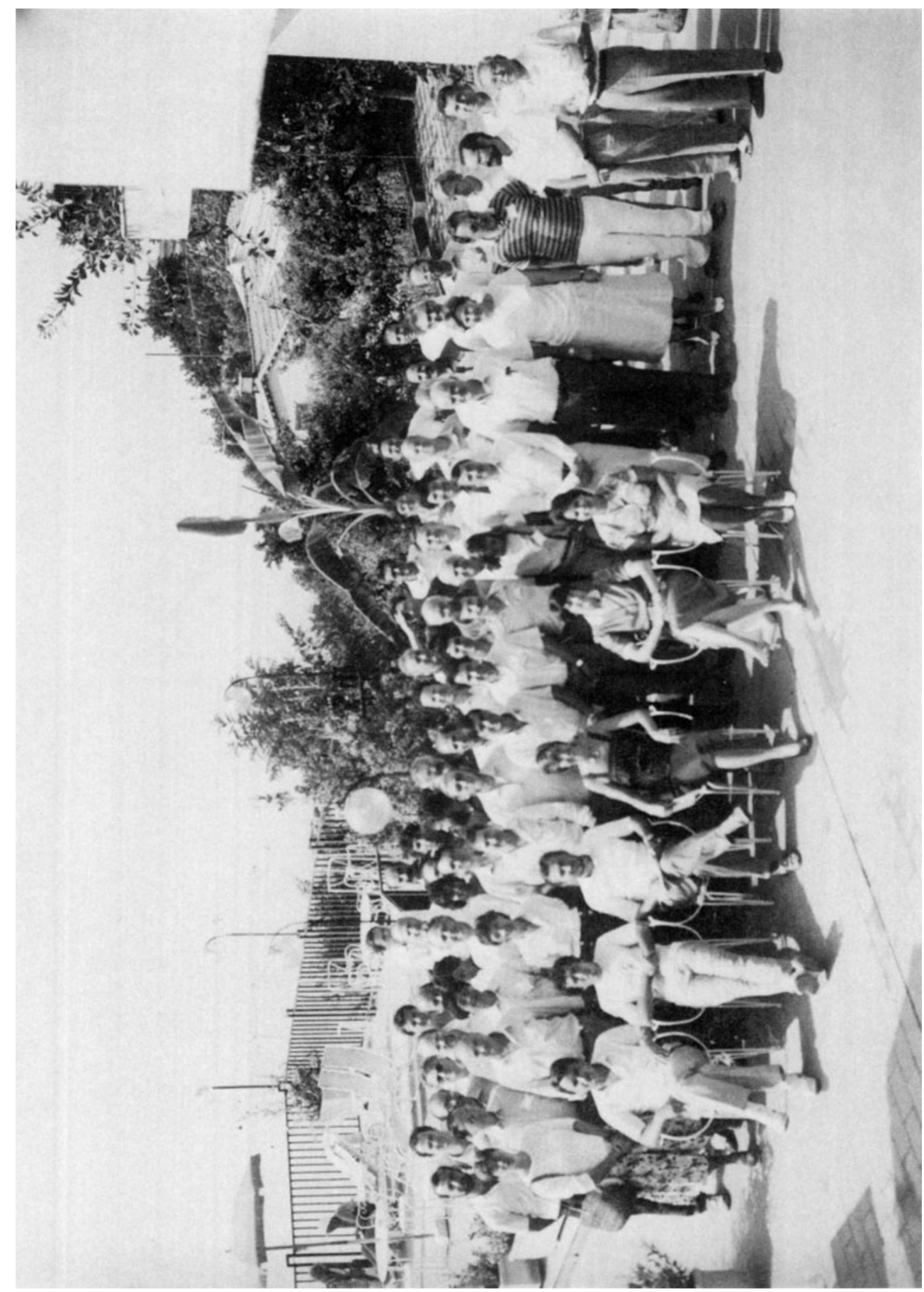

